\title{
SOBRE A COMPAIXÃo NA POLÍTICA: O PONTO DE VISTA DE ARENDT
}

\author{
José João Neves Barbosa Vicente ${ }^{1}$ \\ Universidade Federal do Recôncavo da Bahia (UFRB) \\ (i) https://orcid.org/0000-0001-6823-3933 \\ E-mail: josebvicente@bol.com.br
}

\section{RESUMO:}

Quando o tema em questão é o pensamento político contemporâneo, os estudos de Arendt são indispensáveis. Ela se tornou uma referência nesse assunto, desde a publicação da sua obra Origens do totalitarismo. Neste artigo, no entanto, o objetivo não é discutir ou analisar o conceito de política dessa autora e nem relacioná-lo necessariamente a uma determinada teoria ou forma de governo, mas sim apresentar de modo introdutório e elementar, alguns aspectos das suas considerações e dos seus posicionamentos sobre o sentimento de compaixão na política como entendida por ela, especialmente como aparecem em sua obra Da revolução.

PALAVRAS-CHAVE: Arendt; Compaixão; Política; Sofrimento; Solidariedade.

\section{ON COMPASSION IN POLITICS: ARENDT'S POINT OF VIEW}

\begin{abstract}
:
When the subject in question is contemporary political thought, Arendt's studies are indispensable. She has become a reference in this subject since the publication of her work The Origins of Totalitarianism. In this article, however, the objective is not to discuss or analyze the concept of this author's policy or necessarily relate it to a particular theory or form of government, but to present in an introductory and elementary way, some aspects of her considerations and positions on the feeling of compassion in politics as understood by her, especially as they appear in her work On Revolution.
\end{abstract}

KEYWORDS: Arendt; Compassion; Policy; Suffering; Solidarity.

\footnotetext{
${ }^{1}$ Professor de Filosofia da Universidade Federal do Recôncavo da Bahia (UFRB), Amargosa - BA, Brasil.
}

VICENTE, José João Neves Barbosa. Sobre a compaixão na política: o ponto de vista de Arendt. Griot : Revista de Filosofia, Amargosa-BA, v.20, n.2, p.281-290, junho, 2020. 
Arendt ocupa lugar de destaque na história do pensamento ocidental e suas ideias ou “opiniões", como disse Fry (2010, p.11), "não são facilmente rotuladas". Escreveu com clareza e abriu mão dos "jargões filosóficos" porque queria que suas ideias chegassem também ao "público em geral" e não apenas às "plateias meramente acadêmicas". Tratou de diversos assuntos, mas manteve a coerência: "cada livro que ela acrescentava ao seu corpus explorava um aspecto adicional que explicava com mais detalhes o resto de sua teoria". Desde a publicação da sua obra Origens do totalitarismo, Arendt se tornou imprescindível quando o tema em questão é a política que, para ela, não pode existir sem a liberdade, esta é a sua razão de ser, seu sentido original. Essa liberdade defendida de forma vigorosa por Arendt, não é parte constitutiva do ser de cada um de nós, mas sim construída no mundo quando agimos em conjunto. Em termos arendtianos, nascemos "para a liberdade", não livres; tornamo-nos livres por meio de atos e palavras em um espaço público na presença de nossos pares, sem barreiras, restrições ou censuras à fala ou à opinião do outro. Nesse sentido, é preciso respeitar rigorosamente a "pluralidade humana", a existência de diversos iguais, a "coexistência e associação de homens diferentes" (ARENDT, 2009a, p.145). A partir do seu conceito de política, Arendt recusa qualquer tipo de teoria, forma de governo ou sentimento que se incline a diminuir, enfraquecer ou eliminar a sua razão de ser e dificultar ou impedir o debate, a discussão, a ação, a fala do outro e a diversidade de opiniões em um espaço público. Todavia, é importante sublinhar que não se pretende aqui analisar especificamente o conceito de política dessa autora e nem relacioná-lo necessariamente a uma determinada teoria ou forma de governo. O objetivo é simplesmente apresentar de modo introdutório e elementar, alguns aspectos das suas considerações e dos seus posicionamentos sobre o sentimento de "compaixão" na política como entendida por ela, especialmente como aparecem em sua obra Da revolução.

A compaixão é um assunto sobre o qual, como disse Berlant $(2004$, p.1), "não há nada claro"; sabemos simplesmente "que ela implica em uma relação social entre espectadores e sofredores". Nas palavras de Mosterín (2014, p.25), que parecem se alinhar com o que disse Rousseau (1989, p.74) no "Século das Luzes", trata-se de uma "emoção moral desagradável que sentimos ao nos colocarmos imaginativamente no lugar do outro que sofre". Seja como for, esse tipo de sentimento, como afirmou Orwin (1998, p.308), é humano "na sua essência [...] e totalmente deste mundo". Ter compaixão por alguém é algo "natural"; para Solomon (2004, p.43), é um "requisito mínimo" para sermos pessoas decentes. No entanto, infelizmente, a compaixão pode também ser usada "instrumentalmente e perversamente", como sublinhou Frost (2014, p.54), ainda que "seu valor moral fundamental" seja "bom, interpessoal e afetivo". Na "teoria política", a compaixão é um sentimento conhecido, pelo menos desde o século XVIII, e Rousseau, nas palavras de Arendt (2008, p.20), foi o seu "maior e historicamente mais efetivo defensor". De acordo com Ure e Frost (2014, p.2), a compaixão já "foi aclamada como a principal virtude democrática", mas também já foi "condenada como politicamente tóxica". A verdade é que pouco se sabe sobre "os usos e abusos" desse tipo de sentimento na política, mas não se pode negar que ele se manifesta constantemente nessa esfera, na maioria das vezes, como tema central dos discursos proferidos por políticos e governantes. E se "existe", de fato, "um projeto", como disse Degerman (2019, p.154), "para recuperar as emoções na política hoje", então, as considerações e os posicionamentos de Arendt sobre a compaixão, se mostram relevantes e atuais.

Nos escritos de Arendt sobre política, os "sentimentos" são tratados por ela, de um modo geral, como temas secundários. Na verdade, como disse Merino (2014, p.243-244), os "estados de ânimo que nos abrem para a experiência dos objetos, do outro e do mundo" são, em termos gerais, apenas caminhos para se discutir alguns assuntos em seu pensamento político, mas não 
são temas centrais em sua obra. Isso ocorre, principalmente, porque na política esses "estados de ânimo" são vistos por Arendt como ameaças que contribuem para o desaparecimento da "distância necessária entre a pluralidade de indivíduos que possibilita o espaço público". $\mathrm{O}$ "amor" dos amantes, por exemplo, que, para ela, possui "sua esfera própria" e é guiado essencialmente pela "paixão" que representa a única mediação entre eles, não se encaixa em seu conceito de política que exige diálogo, discussões e debates; nas relações entre amantes não há "espaço" e apenas eles existem. Portanto, por causa da "sua paixão", esse tipo de "amor destrói aquela mediação que estabelece uma relação entre nós e os outros, e deles nos separa". Desse modo, ele "não é apenas apolítico, mas anti-político, talvez a mais poderosa das forças humanas anti-políticas" (ARENDT, 2009, p.254). Para Arendt, em hipótese alguma, o "amor" é ou pode ser uma referência adequada para ação política; baseado em uma "relação direta e pessoal", o “amor" se opõe à esfera pública. Assim, como sublinhou Nunes (2016, p.70), ele "não deve fazer parte argumentativa ou persuasiva no diálogo político, até porque a pluralidade teria de ser sacrificada em nome da experiência de um tipo de sentimento que é íntimo e que requer exclusividade". Trata-se, portanto, de um sentimento íntimo, "extramundano" e que se confunde com a "obscuridade do coração"; o "amor" não cabe no espaço público, porque é incapaz de aceitar a lógica dos debates ou das discussões. É importante, no entanto, não confundir esse tipo de amor com o "Amor mundi: aspecto do mundo que se forma como espaçotempo na medida em que os homens existem no plural" (ARENDT apud CORREIA, 2010, p.817). O amor mundi é o princípio que inspira os homens a preservar o "mundo" como espaço livre, onde possam agir em conjunto por meio de atos e palavras, sem que ninguém perca sua singularidade.

Em relação à "compaixão", Arendt também não tem dúvida do perigo que ela representa para a política. Em termos arendtianos, a compaixão, como observou Gottsen (1994, p.40-42), pertence ao "catálogo" dos sentimentos "potencialmente prejudiciais à liberdade". Não há compatibilidade entre esse tipo de sentimento que, no século XVIII, foi descrito por Rousseau (1989, p.74) como "uma repugnância inata ao ver sofrer seu semelhante", e o âmbito político como entendido por Arendt; não é possível fazer do outro um participante do espaço público, capaz de agir, debater e discutir na presença dos seus pares, porque alguém teve compaixão para com ele. Para Arendt (1988, p.68-69), assim como o "amor", esse tipo de sentimento também "elimina a distância, o espaço material entre os homens, onde se localizam os eventos políticos e todo o universo das relações humanas". A compaixão tem "aversão por qualquer espécie de fala conciliatória ou argumentativa em que alguém fala com alguém sobre algo que é do interesse de ambos"; ainda de acordo com a autora, "esse interesse no mundo, loquaz e argumentativo, é inteiramente estranho à compaixão, que é dirigida unicamente, e com veemente intensidade, para o próprio homem que sofre". Portanto, politicamente falando, o sentimento de compaixão é "irrelevante"; trata-se de um "co-sofrimento" que "apaga" as diferenças e os espaços entre as pessoas e não consegue ultrapassar o que é sofrido por um determinado indivíduo. Ele "aproxima as pessoas, não pela palavra, mas sim pelos gestos ou pelos silêncios" (CAPONI, 1998/1999, p.106). A compaixão elimina o discurso, olha diretamente para aqueles que sofrem e foca nas suas "necessidades urgentes e imediatas", sem qualquer preocupação para que eles participem da "esfera pública", como espaço de diálogo, debates e discussões abertas. É um sentimento que destrói o âmbito político, porque torna a "ação impossível"; por isso, como disse Walt (2012, p.65), a "política" não deve "se preocupar com a compaixão". Esse sentimento precisa ficar fora desse âmbito e não pode ser transformado em seu principal discurso. Para Arendt, como afirmou Canovan (1994, p.194), ter compaixão para com os outros, para com aqueles que sofrem é, de fato, algo "admirável, mas apolítico". Compaixão, portanto, não pode 
ser tomada como "base para a política organizada"; ela tende a obscurecer "o juízo político" e não a orientá-lo.

Se há algum interesse para que a política desempenhe adequadamente o seu papel na sociedade, o sentimento de compaixão precisa permanecer no seu devido lugar; ele precisa ficar confinado "na esfera da intimidade" e jamais permitido "na esfera política" (KING, 2015, p.258). De acordo com Arendt (2008, p.22-23), os antigos que eram "mais experimentados que nós em todos os assuntos políticos", sempre consideraram a compaixão não apenas um sentimento "que pode nos dominar como o medo, sem que possamos resistir a ela", mas também capaz de impossibilitar a "ação". A compaixão não tem espaço no pensamento político de Arendt. Nas palavras da autora, a própria "Historia" nos lembra que, "mesmo durante os longos séculos em que a religião cristã de misericórdia impôs padrões morais à civilização ocidental, a compaixão se manifestava fora do domínio político (ARENDT 1988, p.56). Portanto, para Arendt, se por "longos séculos" esse tipo de sentimento considerado como "algo totalmente natural" e inevitável para o homem" esteve fora do âmbito político, assim deveria permanecer. Os homens não agem politicamente porque são "instigados" ou "compelidos" pelo sofrimento do outro, mas sim porque existe um espaço público onde possam discutir e debater ideias e opiniões na presença de seus pares, sem que ninguém perca a sua singularidade. A compaixão é algo íntimo e incapaz de discurso, ela apenas "fala na medida em que tenha de responder diretamente ao puro som ou gestos expressivos, através dos quais o sofrimento se torna audível e visível para o mundo" (ARENDT, 1988, p.69). Destituído de significado político, a compaixão é incapaz de estabelecer "instituições duradouras". Longe desse sentimento, "as instituições políticas", conforme observou Hayden (2014, p.204), "serão capazes de funcionar como um meio pelo qual a liberdade política pode ter a chance de florescer". Para Arendt (2008, p.33-34) as "coisas do mundo" ganham importância, ou "se tornam humanas para nós", não pelo fato de nos afetar, "instigar e estimular", mas sim "quando podemos discutilas com nossos companheiros". A compaixão, como já foi dito anteriormente, é incapaz de discurso, ela é muda, "cria uma unidade com o outro", elimina os espaços e as diferenças entre os indivíduos.

A "natureza" da compaixão não permite, por exemplo, que ela seja "tocada pelos sofrimentos de toda uma classe, ou de um povo, nem muito menos da humanidade como um todo"; nesse sentido, a característica principal desse tipo de sentimento é "não pode ir além do que é sofrido por uma pessoa" (ARENDT, 1988, p.67). Assim, de acordo com Arendt (1988, p.67-68), "sua força reside na força da própria paixão, a qual, ao contrário da razão, só pode abranger o particular, mas não tem qualquer noção do geral e nenhuma capacidade de generalização". O lugar da compaixão é, para a autora, definitivamente fora da esfera política; ela destrói "o sentido de coletividade, de infindável variedade de uma multidão cuja majestade" reside "em sua própria pluralidade" (ARENDT, 1988, p.74). Não se pode conciliar esse sentimento de foro íntimo e da esfera privada, com a política. Incapaz de "argumentação" e por não ser um "princípio de ação", esse tipo de sentimento não tem condições de "orientar o juízo político". Para a autora, a compaixão não é totalmente silenciosa, mas é preciso destacar que "sua linguagem consiste mais em gestos e expressões faciais do que em palavras" (ARENDT, 1988, p.68). É um "sentimento exacerbado" e sem "limites" que, "paradoxalmente", como escreveu Lafer (1988, p.270), "ao abolir as distâncias", conduz "a uma insensibilidade em relação à realidade em geral e à realidade das pessoas em particular, que oblitera o juízo". A compaixão em termos arendtianos, como observou Wilkinson (2014, p.124), conduz "decisões precipitadas e inspira ações impensadas". É, portanto, uma ameaça à política; quando entra nesse espaço, alerta Sznaider (2001, p.4), ela "leva à crueldade". Apesar de ser politicamente 
"irrelevante", porque como destacou Bourgault (2011), ela não pode ser "ouvida", por ser "muito íntima", mas também porque não pode ser "observada" e nem pode aparecer, quando entra na política e, por meio dela, age no intuito de aliviar o sofrimento dos indivíduos ou "melhorar", nas palavras de Arendt (2008, p.22), "o quinhão dos infelizes, ao invés de estabelecer justiça para todos", a compaixão provoca consequências desastrosas.

É importante sublinhar que Arendt não condena ou recusa o sentimento de compaixão em si. Para ela, esse sentimento é "inquestionavelmente um afeto material natural que toca, de forma involuntária, qualquer pessoa normal à vista do sofrimento, por mais estranho que possa ser o sofredor" (ARENDT, 2008, p.22). A autora também não ignora "a questão do desprendimento pessoal, ou antes, a questão da abertura aos outros, que é de fato a precondição para a 'humanidade', em qualquer acepção do termo" (ARENDT, 2008, p.23). Sua preocupação, como disse Degerman (2019, p.165), é “simplesmente observar que não podemos basear a ação política na compaixão porque a política exige pluralidade e diálogo, e a compaixão é singular e sem palavras". Ela também quer alertar para o perigo desse sentimento na política, para os danos que ele possa provocar, quando entra nessa esfera e a utiliza para melhorar as condições matérias e aliviar as dores daqueles que sofrem. Arendt não é, portanto, insensível, por exemplo, ao sofrimento daqueles que se encontram no estado de "pobreza", apenas entende que não existe nada "mais obsoleto do que a tentativa de libertar a humanidade da pobreza por meios políticos; nada pode ser mais inútil e mais perigoso" (ARENDT, 1988, p.90). Não há nada de errado em ter compaixão para com aqueles que sofrem no estado de pobreza, isso é um "afeto natural", o perigo é quando esse sentimento se apodera da política e, por meio dela, busca libertar os indivíduos desse estado. Para preservar o sentido ou a razão de ser da política, isto é, a liberdade, a compaixão precisa ficar fora da esfera política; ela é um empecilho ao debate, à discussão, à argumentação e à troca de opiniões. As "tentativas" dos homens no sentido "de construir programas políticos a partir da compaixão generalizada por classes de pessoas", como observou Canovan (1994, p.194) em um dos seus estudos sobre o pensamento político de Arendt, "geram um sentimento autoindulgente de piedade que obscurece o juízo político, e levam aqueles que o professam a usar da violência em uma vã tentativa de demonstrar sua própria sinceridade". A compaixão não tem paciência, não espera; como destacou Arendt (1988, p.69), diferente da política, ela não se submete, por exemplo, aos "demorados e extenuantes processos de persuasão, negociação e acordo". Ainda nas palavras da autora, a compaixão "empresta sua voz ao próprio sofrimento, que deve clamar por ação direta e rápida, isto é, ação com os meios de violência". A Revolução Francesa é, para Arendt, um dos exemplos claro do dano que esse tipo de sentimento pode causar à política.

Em seus estudos desenvolvidos em sua obra Da revolução, Arendt conclui que a Revolução Francesa fracassou em sua tentativa de realizar o "ato de fundação", ela não conseguiu, portanto, recriar a política como espaço de manifestação da liberdade ou do "agir em concerto". Esse "fracasso", no entanto, não está ligado, por exemplo, à incompetência ou à falta de liderança dos homens da revolução, mas sim à compaixão desses homens para com o sofrimento daqueles que viviam em situação de "pobreza"; tal situação, nas palavras de Arendt (1988, p.48), "é mais do que a privação, é um estado de constante carência e aguda miséria, cuja ignomínia consiste em sua força desumanizadora". Diante da pobreza que é "abjeta, porque submete os homens ao império absoluto de seus corpos, isto é, ao império absoluto da necessidade", os homens da revolução substituíram a "liberdade" pela "necessidade"; em outras palavras, o impulso da revolução deixou de ser a "liberdade" e passou a ser a "compaixão" diante de uma multidão que sofria no estado de extrema pobreza. Não se "buscava mais a liberdade; seu objetivo agora era a felicidade do povo". Portanto, o sofrimento da "multidão dos 
pobres" impulsionou a Revolução Francesa "para frente" e se tornou, não apenas seu argumento ou discurso político mais importante, mas também o objetivo da sua ação; aos homens da Revolução Francesa interessava apenas "emancipar o povo, não qua cidadãos em perspectiva, mas qua malheureux" (ARENDT, 1988, p.88). A compaixão, como sublinhou BERKOWITZ (2018, p.52), foi elevada "ao grau de suprema paixão política" e à sua "mais alta virtude". A compaixão desses homens diante do sofrimento da "multidão dos pobres" mudou todo o rumo da Revolução Francesa, eles passaram a se preocupar com a libertação da pobreza, não com a liberdade; resolveram "melhorar o quinhão dos infelizes, ao invés de estabelecer justiça para todos" (ARENDT, 2008, p.22). E como destacou Arendt (1988, p.48), "foi a necessidade, as urgentes carências do povo" que vivia no estado de pobreza, "que desencadeou o terror e levou a Revolução à sua ruína"; ainda de acordo com a autora, Robespierre estava ciente do que "estava ocorrendo", ele sabia que tinham perdido "a ocasião oportuna de fundar a liberdade", que tinham perdido o "momento histórico" (ARENDT, 1988, p.48). Portanto, o "fracasso" da Revolução Francesa está diretamente ligado à compaixão dos homens da revolução diante da "necessidade e da pobreza"; fizeram dessa situação o principal objetivo de suas ações e tentaram libertar o "povo" dessas amarras por meios políticos.

A compaixão que, para Arendt, (1988, p.64), foi introduzida "na teoria política" por Rousseau e levada "à praça pública" por Robespierre "com a veemência de sua grande oratória revolucionária", foi crucial para ofuscar o desejo dos homens da Revolução Francesa e desviar seus objetivos originais; devido "a intensidade desmedida de seus sentimentos", esses homens "não sentiam nenhum remorso em sacrificar a seus "princípios', ou ao curso da História, ou à causa da revolução" (ARENDT, 1988, p.71). Quando a "multidão dos pobres" veio ao encontro deles, o sentimento de compaixão falou mais alto do que o desejo de criar um espaço para a liberdade pública. Assim, concentraram seus esforços no sentido de libertar o "processo vital da sociedade dos grilhões da escassez, e fazê-lo volumar-se numa torrente de abundância" (ARENDT, 1988, p.51); eles abraçaram a "luta" ou o desejo do "povo" de se libertar do sofrimento provocado pela pobreza. Mas, de acordo com Arendt, como destacou Gündoğdu (2015, p.73), “as ações impulsionadas pela compaixão quase nunca tentam mudar as condições que produzem a injustiça social"; seus interesses se voltam quase sempre para o "alivio imediato do próprio sofrimento". A compaixão exige "ação rápida e direta"; assim, dispensa a política e os processos legais baseados no diálogo, negociações e acordos, para "adotar meios violentos para alcançar seus objetivos". Esse tipo de sentimento desempenha "papel desastroso" quando "aplicado ao domínio político"; ele não é dessa esfera, "sua intrusão nesse domínio", afirma Amiel (2003, p.45), "só pode ser violenta". A compaixão não consegue "mudar o mundo" através do diálogo, da discussão, do debate ou da negociação, porque como já foi dito anteriormente, além de muda e incapaz de argumentação, ela é também impaciente e exige rapidez e objetividade nas ações que, raramente, acontecem sem violência. Na variedade, como disse Parekh (2008, p.118), “a violência é o resultado necessário de uma compaixão que não pode ser articulada na fala". Portanto, como disse Amiel (2003, p.43), se na Revolução Francesa "houve terror e violência, eles provêm precisamente da compaixão: os revolucionários nada têm de intrinsecamente sanguinário ou violento". A compaixão, por mais nobre que possa ser, não tem espaço na política como entendida por Arendt; ela elimina a pluralidade e impossibilita a ação.

Em termos arendtianos, dizer que a compaixão não tem espaço na política e precisa ficar fora desse âmbito devido a sua "natureza", não significa afirmar que a política deva ignorar aqueles que sofrem, mas sim que existem formas politicamente relevantes de sermos "generosos" com os outros. Ou "seriam os seres humanos tão mesquinhos a ponto de serem incapazes de agir 
humanamente, a menos que sintam instigados e por assim dizer compelidos pela sua própria dor, ao ver outros sofrerem?" (ARENDT,2008, p.23). Arendt acredita que, diante do sofrimento das pessoas, uma das alternativas ao sentimento de compaixão é a solidariedade. Para a autora, a solidariedade, ao contrário da compaixão, é politicamente relevante e enxerga o outro como um ser humano com quem é possível estabelecer uma "comunidade de interesses". Sem apelar "à paixão da compaixão ou ao sentimento de piedade", a solidariedade, como observou BERKOWITZ (2018, p.53), se baseia na ideia kantiana "de uma "mentalidade alargada" que permite "pensar a partir da perspectiva dos outros". A solidariedade não olha para o outro como um necessitado carente de ajuda, mas sim "como um igual" com capacidade para dialogar, debater, opinar e posicionar. Na solidariedade as diferenças são respeitadas e a pluralidade não é ameaçada, ela é entendida e admitida em sua totalidade, isto é, como "a condição da ação humana pelo fato de sermos todos os mesmos, isto é, humanos, sem que ninguém seja exatamente igual a qualquer pessoa que tenha existido, exista ou venha a existir" (ARENDT, 2009, p.16). Para Arendt, o sofrimento das pessoas poderá ser superado, não através da compaixão que pertence à "esfera da intimidade", mas sim por meio de uma "ação" que, em termos políticos, chama-se solidariedade, cujo objetivo são os interesses comuns entre as pessoas e não a vida deste ou daquele indivíduo em particular. A solidariedade não é um "sentimento" que tem "em si próprio seu prazer" e nem se constitui em "uma atração pelos homens fracos que reforce a polaridade entre posições dissimétricas". O seu "fundamento" está "na simetria dos interesses, numa 'desapaixonada comunidade de interesses' com os infortunados, na medida em que todos compartilham uma única preocupação por universalizar a "dignidade humana" (CAPONI, 1998/1999, p.109). A conexão entre as pessoas por meio da solidariedade, como entendida por Arendt, além de não eliminar suas diferenças, ela permite que, cada uma delas, entre no espaço público e participe dela. Para a autora, como disse KOHN (2005, p.142), "a solidariedade é a virtude política cardinal e é indispensável à ação, à entrada em uma esfera pública que rompe as correntes da existência privada e ilumina a "liberdade do mundo". A solidariedade tem condições de superar o sofrimento e orientar o "juízo político".

A solidariedade permite sair do foro íntimo e da esfera privada, ela "entra em praça pública" ou esfera política, sem oferecer nenhum risco: "terminologicamente, a solidariedade é o princípio que pode inspirar e guiar a ação" (ARENDT, 1988, p.71). Como disse Caponi (1998/1999, p.109), ela "supera o vínculo imediato do co-sofrimento", porque "não é silenciosa nem gestual, mas sim precisa da mediação das palavras e do diálogo, para poder generalizar-se"; a solidariedade toma "como ponto de partida as diferenças, uma pluralidade humana considerada irredutível". É verdade que não se pode negar, por exemplo, que a história do "discurso da solidariedade" é longa e diversa, mas, "especificamente", como sublinharam Hayden e Saunders (2019, p.183-184), ela "é um 'tipo de ação" sustentado por um comprometimento coletivo de 'estar juntos', seja para promover algum objetivo político comum ou para superar alguma dificuldade, ameaça ou injustiça". Ainda de acordo com esses autores, esse tipo de ação "significa criar livremente relações de reconhecimento mútuo, respeito e obrigação entre pessoas desconhecidas". Em termos arendtianos, ao contrário do sentimento de compaixão, a ação solidária possui um caráter político, sem qualquer ameaça à pluralidade humana. Através dela, afirma Arendt (1988, p.70), os homens "estabelecem, deliberadamente, e como que desapaixonadamente, uma comunidade de interesses com os oprimidos e os explorados". Ainda de acordo com a autora, "a solidariedade, embora possa ser suscitada pelo sofrimento, não é por ele guiada, e compreende tanto os fortes e os ricos, como os fracos e os pobres"; o comprometimento da ação solidária é, fundamentalmente, "com “ideias" - grandeza, ou honra, ou dignidade - do que com qualquer "amor' pelos homens". Ela proporciona uma

VICENTE, José João Neves Barbosa. Sobre a compaixão na política: o ponto de vista de Arendt. Griot : Revista de Filosofia, Amargosa-BA, v.20, n.2, p.281-290, junho, 2020. 
relação entre os homens e preserva a possibilidade da ação política entre eles, sem qualquer ameaça à sua condição plural. A solidariedade compartilha "da razão, e, portanto, da generalidade" e "é capaz de abranger, conceitualmente, uma coletividade" que não se resume simplesmente em uma "classe", "nação" ou "um povo, mas, eventualmente, toda a humanidade" (ARENDT, 1988, p.70). Uma ação solidária não age para identificar o sofrimento das vítimas, mas sim para reconhecê-las como "membros iguais de um mundo comum, cuja humanidade foi injustamente negada e que deve ser restaurada em seu status como seres de ação" (MROVLJE, 2019, p.112). Nas palavras de Arendt (1988, p.70), "o interesse comum" da solidariedade com as vítimas, "seria então 'a grandeza do homem', ou a 'honra da raça humana', ou a dignidade do homem". A solidariedade é mediada pelo diálogo, ela respeita a opinião, a posição, a individualidade e a singularidade daqueles que sofrem; além superar o sofrimento, a solidariedade permite que todos entrem no "espaço público" e participem através da ação em conjunto. 


\section{Referências}

AMIEL, Anne. A não-filosofia de Hannah Arendt: revolução e julgamento. Trad. João C. S. Duarte. Lisboa: Piaget, 2003.

ARENDT, Hannah. Da revolução. Trad. Fernando Dídimo Vieira. Brasília: UnB, 1988.

ARENDT, Hannah. Homens em tempos sombrios. Trad. Denise Bottmann. São Paulo: Companhia das Letras, 2008.

ARENDT, Hannah. A condição humana. Trad. Roberto Raposo. Rio de janeiro:

Forense, 2009.

ARENDT, Hannah. A promessa da política. Trad. Pedro Jorgensen Jr. Rio de Janeiro: DIFEL, 2009 a.

BERKOWITZ, Roger. Protest and democracy: Hannah Arendt and the foundation of freedom. Stasis, v.6, n.1, p.36-55, 2018.

BERLANT, Lauren. Introduction: compassion (and withholding). In: BERLANT, Lauren (Ed.). Compassion: the culture and politics of an emotion. Routledge 2004.

BOURGAULT, Sophie. Hannah Arendt, compassion et politique. Implications philosophiques, 2011. Disponível em: http://www.implications-philosophiques.org/semainesthematiques/passions-dans-lespace-public/hannah-arendt-compassion-et-politique/. Acessado em: 15/07/2019.

CANOVAN, Margaret. Politics as culture: Hannah Arendt and the public realm. In: HINCHMAN, Lewis \& HINCHMAN, Sandra (Eds.). Hannah Arendt: critical essays. State University of New York Press, 1994.

CAPONI, Sandra. A lógica da compaixão. Trans/Form/Ação, v.21/22, p.91-117, 1998/1999.

CORREIA, Adriano. Natalidade e amor mundi: sobre a relação entre educação e política em Hannah Arendt. Educação e Pesquisa, v.36, n.3, p. 811-822, set./dez. 2010.

DEGERMAN, Dan. Within the heart's darkness: the role of emotions in Arendt's political thought. European Journal of Political Theory, v.18, n.2, p.153-173, 2019.

FROST, Lola. Compassion as risk. In: URE, Michael \& FROST, Mervyn (Eds). The politics of compassion. Routledge, 2014.

FRY, Karin. Compreender Hannah Arendt. Trad. Paulo Ferreira Valério. Petrópolis: 2010.

GOTTSEN, Michael. The political thought of Hannah Arendt. SUNY, 1994.

GÜNDOĞDU, Ayten. Rightlessness in an Age of Rights. Hannah Arendt and the Contemporary Struggles of Migrants. Oxford University Press, 2015.

HAYDEN, Patrick (Ed.). Hannah Arendt: Key Concepts. Routledge, 2014.

HAYDEN, Patrick \& SAUNDERS, Natasha. Solidarity at the margins: Arendt, refugees, and the Inclusive politics of world-making. In: HIRUTA, Kei (Ed.). Arendt on freedom, liberation and revolution. Palgrave Macmillan, 2019.

KING, Richard. Arendt and America. Chicago: The University of Chicago Press, 2015.

KOHN, Carlos. Teoría y práctica del republicanismo cívico: La perspectiva arendtiana. Filosofia Unisinos, v.6, n.2, p.138-148, maio/ago 2005.

LAFER, Celso. A reconstrução dos direitos humanos: um diálogo com o pensamento de Hannah Arendt. São Paulo: Companhia das Letras, 1988.

MERINO, María José López. Indignación política: Reflexiones desde el pensamiento de H. Arendt. Alpha, n.38, p.243-252, Julio, 2014. 
MOSTERíN, Jesús. El triunfo de la compasión: nuestra relación con los otros animales. Alianza Editorial, 2014.

MROVLJE, Maša. Rethinking political judgement: Arendt and existentialism. Edinburgh University Press, 2019.

NUNES, Igor Vinícius Basílio. Amor mundi e espírito revolucionário: Hannah Arendt entre política e ética. Cadernos de Filosofia Alemã, v.21, n.3, p.67-78, dez. 2016.

ORWIN, Clifford. Rousseau, a compaixão e as crises da modernidade. Trad. Manuela Pena Gomes. Análise Social, v.XXXIII, n.146/147, p.307-321, 1998.

PAREKH, Serena. Hannah Arendt and the challenge of modernity: a phenomenology of human rights. Routledge, 2008.

ROUSSEAU, Jean-Jacques. Discurso sobre a origem e os fundamentos da desigualdade entre os homens. Trad. Iracema Gomes Soares e Maria Cristina Roveri Nagle. Brasília: Editora Universidade de Brasília; São Paulo: Ática, 1989.

SOLOMON, Robert. In defense of sentimentality, Oxford University Press, 2004.

SZNAIDER, Natan. The compassionate temperament: care and cruelty in modern society. Rowman \& Littlefield, 2001.

URE, Michael \& FROST, Mervyn. Introduction. In: URE, Michael \& FROST, Mervyn (Eds.). The politics of compassion. Routledge, 2014.

WALT, Johan van der. Law and the space of appearance in Arendt's thought. In: GOLDONI, Marco \& MCCORKINDALE, Christopher (Eds.). Hannah Arendt and the law. Hart Publishing, 2012.

WILKINSON, Iain. The new social politics of pity. In: URE, Michael \& FROST, Mervyn (Eds.). The politics of compassion. Routledge, 2014.

Autor(a) para correspondência: José João Neves Barbosa Vicente, Avenida Nestor de Melo Pita, 535, Centro, 45300-000, Amargosa - BA, Brasil. josebvicente@bol.com.br 